\title{
Author Correction: Commensal microflora-induced T cell responses mediate progressive neurodegeneration in glaucoma
}

\author{
Huihui Chen 1,2,3,4, Kin-Sang Cho (10) ${ }^{3,4}$, T.H.Khanh Vư 3,4,5, Ching-Hung Shen ${ }^{6,7}$, Mandeep Kaur 6,7 , \\ Guochun Chen 3,4,8, Rose Mathew ${ }^{3}$, M. Lisa McHam9 ${ }^{9}$, Ahad Fazelat ${ }^{3}$, Kameran Lashkari, 3 , \\ Ngan Pan Bennett Au ${ }^{10}$, Joyce Ka Yu Tse ${ }^{10}$, Yingqian Li $i^{3,4}$, Honghua Yu, ${ }^{3,4}$ Lanbo Yang ${ }^{3}$, Joan Stein-Streilein ${ }^{3,4}$, \\ Chi Him Eddie Ma ${ }^{10,11,12}$, Clifford J. Woolf (1) 11,12, Mark T. Whary ${ }^{13,14}$, Martine J. Jager (1) 5, James G. Fox ${ }^{13,14}$, \\ Jianzhu Chen ${ }^{6,7} \&$ Dong F. Chen (1) ${ }^{3,4}$
}

Correction to: Nature Communications; https://doi.org/10.1038/s41467-018-05681-9; published online 10 August 2018

The originally published version of this Article contained an error in Fig. 4. The bar chart in panel $\mathrm{f}$ was inadvertently replaced with a duplicate of the bar chart in panel e. This error has now been corrected in both the PDF and HTML versions of the Article.

Published online: 20 September 2018

(i) Open Access This article is licensed under a Creative Commons Attribution 4.0 International License, which permits use, sharing, adaptation, distribution and reproduction in any medium or format, as long as you give appropriate credit to the original author(s) and the source, provide a link to the Creative Commons license, and indicate if changes were made. The images or other third party material in this article are included in the article's Creative Commons license, unless indicated otherwise in a credit line to the material. If material is not included in the article's Creative Commons license and your intended use is not permitted by statutory regulation or exceeds the permitted use, you will need to obtain permission directly from the copyright holder. To view a copy of this license, visit http://creativecommons.org/licenses/by/4.0/.

(c) The Author(s) 2018

\footnotetext{
${ }^{1}$ Department of Ophthalmology, Second Xiangya Hospital of Central South University Changsha, Hunan Province 410011 Hunan, China. ${ }^{2}$ Institution of Ophthalmic Center, Changsha, Hunan Province 410011 Hunan, China. ${ }^{3}$ Schepens Eye Research Institute of Massachusetts Eye and Ear, Harvard Medical School, Boston 02114 MA, USA. ${ }^{4}$ Department of Ophthalmology, Harvard Medical School, Boston 02114 MA, USA. ${ }^{5}$ Department of Ophthalmology, Leiden University Medical Center, 2333 ZA Leiden, The Netherlands. ${ }^{6}$ Koch Institute for Integrative Cancer Research, Massachusetts Institute of Technology, Cambridge 02139 MA, USA. ${ }^{7}$ Department of Biology, Massachusetts Institute of Technology, Cambridge 02139 MA, USA. ${ }^{8}$ Department of Nephrology, Second Xiangya Hospital of Central South University, Changsha 410011 Hunan, China. ${ }^{9}$ Massachusetts Eye Health Service, Boston 02124 MA, USA.

${ }^{10}$ Department of Biomedical Sciences, City University of Hong Kong, Tat Chee Avenue, Hong Kong, China. ${ }^{11}$ F.M. Kirby Neurobiology Center, Children's Hospital Boston, Harvard Medical School, Boston 02115 MA, USA. ${ }^{12}$ Department of Neurobiology, Harvard Medical School, Boston 02115 MA, USA.

${ }^{13}$ Department of Biological Engineering, Massachusetts Institute of Technology, Cambridge 02139 MA, USA. ${ }^{14}$ Division of Comparative Medicine, Massachusetts Institute of Technology, Cambridge 02139 MA, USA. Correspondence and requests for materials should be addressed to J.C. (email: jchen@mit.edu) or to D.F.C. (email: dongfeng_chen@meei.harvard.edu)
} 